\title{
Different clinical spectrum of leptospirosis
}

\author{
Fatma Deniz Aygün ${ }^{1}$, Pınar Özge Avar-Aydın², Haluk Çokuğraş ${ }^{1}$, Yıldız Camcıŏ̆lu ${ }^{1}$ \\ ${ }^{1}$ Division of Pediatric Infectious Diseases, Clinical Immunology and Allergy, ${ }^{2}$ Department of Pediatrics, Istanbul University \\ Cerrahpasa Faculty of Medicine, Istanbul, Turkey. E-mail: avarozge@hotmail.com \\ Received: 5 June 2015, Revised: 10 June 2015, Accepted: 7 September 2015
}

SUMMARY: Aygün FD, Avar-Aydın PÖ, Çokuğraş H, Camcıoğlu Y. Different clinical spectrum of leptospirosis. Turk J Pediatr 2016; 58: 212-215.

Leptospirosis is a prevalent zoonotic disease. Human infection usually occurs through exposure to environmental sources. Clinical course of leptospirosis is variable. We presented five patients, aged between 4-14 years, having a history of contact with rodents and symptoms 7-10 days after contact. The first three cases were relatives and had contact with dead rats after applying insecticides to bakery across from their house. The first case diagnosed as isolated meningitis, others as flu-like illness. The fourth case had a contact history with a rat inundate in the canalization and diagnosed as acute hepatitis. The last case, living in a village with poor sanitation, developed secondary hemophagocytic syndrome. ELISA was performed for diagnosis. High dose penicillin and additional immunosuppressive drugs for the last case were used. All cases showed recovery within 10 days. Leptospirosis should be considered in any patient presenting with an abrupt onset or prolonged fever, myalgia, headache and jaundice.

Key words: leptospirosis, meningitis, hemophagocytic syndrome, childhood.

Leptospirosis is a common zoonotic disease caused by pathogenic spirochetes the genus Leptospira. Various mammals, especially rodents and dogs, are natural hosts. The disease is transmitted to humans incidentally by exposure to urine of the infected mammalian reservoirs that excrete organisms by the urine asymptomatically ${ }^{1,2}$.

Although the majority of the cases occur in tropical and subtropical areas, the disease has a worldwide distribution ${ }^{3,4}$. However leptospirosis is an under-reported disease, and there are no reliable global incidence diagrams. The incidence in temperate climates is increasing and travel-related leptospirosis is also reported especially in groups incorporated in water sports ${ }^{5}$.

The disease has a widespread presentation ranging from asymptomatic forms to severe presentations complicated by multiorgan failure. Weil's disease, the most severe form of leptospirosis, is characterized by jaundice, renal failure and disseminated hemorrhage.

We present five patients, all of them having a history of contact with rodents, admitted with different clinical manifestations, including two only with fever, one with aseptic meningitis, one with acute hepatitis and one with hemophagocytic syndrome due to leptospirosis (Table I).

\section{Case Reports}

\section{Case 1}

A 9-year-old boy admitted with high-grade fever, headache and vomiting who had played with dead rats one week before. Upon physical examination, he was oriented; body temperature was $39^{\circ} \mathrm{C}$ and blood pressure $100 / 70 \mathrm{~mm}$ $\mathrm{Hg}$. Neck rigidity and positive Kernig's sign were found and other examination findings were normal. Fundus examination showed no papilledema. Hemogram and serum biochemical tests were normal. Elevated C-reactive protein (CRP, $2.5 \mathrm{mg} / \mathrm{dl}$ ) and erythrocyte sedimentation rate (ESR, $40 \mathrm{~mm} /$ hour) were found. Cranial imaging was normal. Cerebrospinal fluid analysis revealed normal protein and glucose levels. Seventy cells per $\mathrm{mm}^{3}$ with $90 \%$ leukocytes and spirochetes were seen on microscopic examination. Leptospira IgM enzyme-linked immunosorbent assay (ELISA) 
of cerebrospinal fluid was found positive. He was diagnosed as leptospirosis and recovered after intravenous crystalline penicillin treatment in a week.

\section{Case 2}

Cousin of the first case, 6-year-old girl, living in the same block and also having contact with dead rats admitted with fever one day after him. On physical examination, she had $2 \times 2 \mathrm{~cm}$ tendered cervical lymphadenopathy and otherwise normal physical examination with $37.5^{\circ} \mathrm{C}$ body temperature. She had mild leukocytosis $\left(12,500 / \mathrm{mm}^{3}\right)$, elevated CRP (6 $\mathrm{mg} / \mathrm{dl}$ ) and ESR (28 mm/hour) with normal serum biochemical tests. Because of having the same history, leptospirosis was highly suspected and confirmed by positive leptospira IgM ELISA. She recovered with intravenous crystalline penicillin.

\section{Case 3}

A 4-year-old girl who is sister of the second and cousin of the first case was admitted with fever ten days after playing with dead rats. Her physical examination was completely normal with $37.5^{\circ} \mathrm{C}$ body temperature. Hemogram and serum biochemical findings were normal except raised CRP $(16 \mathrm{mg} / \mathrm{dl})$ and ESR $(25 \mathrm{~mm} /$ hour). Leptospira IgM ELISA was positive and she also recovered after the same treatment.

\section{Case 4}

An 8-year-old boy admitted with malaise, jaundice, dark urine and impaired general condition having contact with a rat inundate in the home canalization water a week before his admission. On physical examination, he was icteric and had $3 \mathrm{~cm}$ tendered hepatomegaly with normal vital signs. His laboratory tests showed normal hemogram, elevated serum bilirubin levels and liver enzymes (total bilirubin $7.63 \mathrm{mg} / \mathrm{dl}$, direct bilirubin $6.34 \mathrm{mg} /$ $\mathrm{dl}$, alanine transaminase 1,037 IU/L, aspartate transaminase 1,310 IU/L, gamma glutamyl transferase $591 \mathrm{IU} / \mathrm{L}$ ), normal coagulation parameters and bilirubin positive urine analysis. Hepatitis A, B, C markers were found negative. Leptospirosis was clinically suspected because of poor sanitation and rat contact which was further confirmed by the positive serum IgM ELISA. He showed a significant recovery after the initiation of intravenous crystalline penicillin in 10 days.

\section{Case 5}

A 14-year-old boy presented with high-grade fever for 15 days and myalgia. He was living in absence of sanitation and having the history of contact with rats. On physical examination, he was febrile $\left(39^{\circ} \mathrm{C}\right)$ with normal vital signs and systemic examination. Eye examination was normal. He had leukocytosis (17,300/ $\mathrm{mm}^{3}$ ) with normal hemoglobin and platelet levels, elevated CRP (15 mg/dl) and ESR (83 $\mathrm{mm}$ /hour), normal coagulation parameter and urine analysis. Chest radiography was normal. Intravenous ceftriaxone was started empirically. After one week of admission, fever persisted and hepatosplenomegaly developed (liver $3 \mathrm{~cm}$ and spleen $1 \mathrm{~cm}$ below the costal margin). Controlled blood tests releaved bicytopenia (hemoglobin $9.1 \mathrm{~g} / \mathrm{dl}$, platelet $100,000 / \mathrm{mm}^{3}$ ) with low ESR level (24 mm/hour), hyperferritinemia $(2,000 \mathrm{ng} / \mathrm{ml})$, hypertriglyceridemia (402 $\mathrm{mg} / \mathrm{dl}$ ), and hypofibrinogenemia (158 mg/ dl). Bone marrow aspiration demonstrated hemophagocytosis without atypical cells. After high dose intravenous steroid $(30 \mathrm{mg} / \mathrm{kg} /$ day for five days), followed by daily oral steroid ( $2 \mathrm{mg} / \mathrm{kg} /$ day) and cyclosporin (100 mg/day), his hematological and biochemical parameters returned to normal ranges. The viral serology, mycoplasma, salmonella, brucella, leishmania serology and tuberculosis results showed no active infection and the cultures of bone marrow and blood remained sterile. As leptospira IgM ELISA was positive, the patient was diagnosed as reactive hemophagocytic syndrome secondary to leptospirosis which he responded well to immunosuppressive and antibiotic treatments and achieved complete recovery within 10 days.

\section{Discussion}

Leptospirosis is an emerging public health problem causing large outbreaks in the tropics, but sporadic cases can also occur in rural and urban areas in temperate zones especially in developing countries. The incidence of leptospirosis varies from $0.1-1 / 100,000$ persons per year in temperate climates to $10-100 / 100,000$ persons per year in the tropics and over 100/100,000 persons per year during outbreaks and in high risk groups, according to WHO report ${ }^{6}$. The diagnosis is confirmed by laboratory tests, but these are not always available, especially in developing countries. For 
Table I. Demographic Features in Cases of Leptospirosis

\begin{tabular}{|c|c|c|c|c|c|}
\hline Features & Case 1 & Case 2 & Case 3 & Case 4 & Case 5 \\
\hline Age (years) & 9 & 6 & 4 & 8 & 14 \\
\hline Gender & Male & Female & Female & Male & Male \\
\hline Transmission & $\begin{array}{c}\text { Animal to } \\
\text { human (rats) }\end{array}$ & $\begin{array}{c}\text { Animal to human } \\
\text { (rats) }\end{array}$ & $\begin{array}{l}\text { Animal to human } \\
\text { (rats) }\end{array}$ & $\begin{array}{l}\text { Animal to human } \\
\text { (rats) }\end{array}$ & $\begin{array}{c}\text { Animal to } \\
\text { human (rats) }\end{array}$ \\
\hline Symptom & $\begin{array}{c}\text { Fever, } \\
\text { headache, } \\
\text { vomiting }\end{array}$ & Fever & Fever & $\begin{array}{l}\text { Malaise, jaundice, } \\
\text { dark urine }\end{array}$ & Fever, myalgia \\
\hline $\begin{array}{l}\text { Diagnostic } \\
\text { method }\end{array}$ & $\begin{array}{c}\text { Microscopic } \\
\text { examination, } \\
\text { Leptospira } \\
\text { IgM }^{*}\end{array}$ & Leptospira IgM* & Leptospira IgM* & Leptospira IgM* & Leptospira $\operatorname{IgM}^{*}$ \\
\hline Diagnosis & Meningitis & Flu-like illness & Flu-like illness & Acute hepatitis & $\begin{array}{l}\text { Hemophagocytic } \\
\text { syndrome }\end{array}$ \\
\hline
\end{tabular}

*: with ELISA (Enzyme-linked immunosorbent assay)

these reasons, leptospirosis is an underreported disease. All of the patients presented above lived in rural areas and with poor sanitation.

Leptospirosis is a biphasic disease; the initial bacteriemic phase is due to direct effect of the spirochete followed by the second immune phase which is due to antigen antibody complex. It is a multiorgan disease having a wide range of clinical course. The most common clinical presentation is mild and selflimited influenza-like illness called anicteric form. Weil's syndrome, the most severe form characterized by jaundice, renal failure and bleeding manifestations, can lead to death. Leptospirosis should be considered in any patient presenting with an abrupt onset of fever, chills, conjunctival suffusion, headache, myalgia and jaundice ${ }^{1,7}$.

Central nervous system involvement is rare, most commonly presenting as aseptic meningitis, which is often asymptomatic, diagnosed only by cerebrospinal fluid examination ${ }^{8}$. Spirochetes can be seen by microscopic examination of cerebrospinal fluid, as seen in Case 1, or urine. Leptospira can reach the cerebrospinal fluid within 48 hours after entering body and can be cultured from the cerebrospinal fluid in early stages of the disease. Isolated or primary meningitis as in Case 1 is rare and usually appears as a component of Weil's disease by immune mediated mechanisms.

Jaundice during leptospirosis can appear within 5-9 days of the anicteric period and may continue for about a month. It can be treated as viral hepatitis but viral serology will be negative. Like other clinical presentations, leptospirosis should be suspected in any patient with jaundice especially if there is a history of contact with contaminated water ${ }^{1,2}$.

Hemophagocytic syndrome, which can be primary or secondary, is characterized by excessive inflammation and tissue destruction due to accumulation of macrophages and $\mathrm{T}$ lymphocytes. Secondary hemophagocytic syndrome occurs after strong immunologic activation such as systemic infection, immunodeficiency, rheumatologic diseases or underlying malignancy. Systemic infections such as typhoid fever, tuberculosis, leishmaniasis and brucellosis were already reported, however leptospirosis associated hemophagocytic syndrome is very rare in the literature ${ }^{9}$. After excluding all other reasons of secondary hemophagocytosis, Case 5 was diagnosed as hemophagocytic syndrome secondary to leptospirosis due to the fever, hepatosplenomegaly, hyperferritinemia, hypofibrinogenemia, cytopenia and hemophagocytosis in the bone marrow and positivity of leptospira IgM ELISA.

Routine laboratory tests to diagnose leptospirosis are generally nonspecific. A left shifted leukocytosis, thrombocytopenia or pancytopenia can occur. Hypokalemia, hyponatremia and renal failure occur during severe forms. Elevated liver enzymes may be observed. Since clinical and laboratory findings are nonspecific, administration of empiric treatment is necessary and diagnosis is frequently made by serologic tests in the setting of high clinical suspicion.

The easiest method for diagnosis of leptospirosis is to see motile spirochetes by dark ground microscopy. Currently, diagnosis 
is based on detection of antibodies against leptospires because culturing leptospires can take months. These antibodies can be detected by microscopic agglutination test, enzyme-linked immunosorbent assay and indirect fluorescent antibody test. Microscopic agglutination test (MAT) is usually considered as a reference test but is only performed at specialized laboratories because of being technically demanding and expensive. It can make serogroup differentiation, but cannot differentiate between acute and past infections because of detecting both $\mathrm{M}$ and $\mathrm{G}$ antibodies ${ }^{10}$. Nowadays, there are some rapid diagnostic tests which provide immediate detection however confirmation by reference test is still recommended. If MAT is not available, ELISA can be performed in suspected cases having the clinical and epidemiological factors of leptospirosis as we stated in our report.

Mild cases of leptospirosis can be treated with ampicillin, amoxycillin, erythromycin and cephalosporins. Severe cases should be hospitalized and treated with high doses of intravenous penicillin (200,000 to $250,000 \mathrm{U} /$ $\mathrm{kg}$ /day). Treatment should be given for 7 to 14 days ${ }^{1}$. Hemodialysis is needed in renal failure. Prompt diagnosis and treatment will avoid complications. By these treatment modalities, mortality is reduced in recent years according to WHO reports.

Since neither the clinical features nor laboratory tests are specific for leptospirosis, a highdegree clinical suspicion is required for early diagnosis even in areas with very low incidence of leptospirosis.

\section{REFERENCES}

1. Long SS, Pickering LK, Prober CG. Principles and Practice of Pediatric Infectious Diseases (4th ed). Philadelphia: Elsevier Churchill Livingstone; 2012: 949-952.

2. Levett PN, Haake DA. Leptospira species (leptospirosis). In: Mandell GL, Bennett JE, Dolin R (ed). Principles and Practice of Infectious Diseases ( $7^{\text {th }}$ ed). Philadelphia: Elsevier Churchill Livingstone; 2009: 3059-3065.

3. Bharti AR, Nally JE, Ricaldi JN, et al. Leptospirosis: a zoonotic disease of global importance. Lancet Infect Dis 2003; 3: 757-771.

4. Pappas G, Papadimitriou P, Siozopoulou V, Christou L, Akritidis N. The globalization of leptospirosis: worldwide incidence trends. Int J Infect Dis 2008; 12 : 351-357.

5. Dupouey J, Faucher B, Edouard S, et al. Human leptospirosis: An emerging risk in Europe? Comp Immunol Microbiol Infect Dis 2014; 37: 77-83.

6. World Health Organization. Human Leptospirosis: Guidance for Diagnosis, Surveillance and Control. WHO; Geneva, Switzerland; 2003. Available at: http://www.who.int/csr/don/en/WHO_CDS_CSR_ EPH_2002.23.pdf

7. Shah I. Leptospirosis. Ped Infect Dis 2012; 4: 4-8.

8. Jha S, Ansari MK. Leptospirosis presenting as acute meningoencephalitis. J Infect Dev Ctries 2010; 4: 179182.

9. Krishnamurthy S, Mahadevan S, Mandal J, Basu D Leptospirosis in association with hemophagocytic syndrome: a rare presentation. Indian J Pediatr 2013; 80: 524-525.

10. Picardeau M, Bertherat E, Jancloes M, Skouloudis AN, Durski K, Hartskeerl RA. Rapid tests for diagnosis of leptospirosis: current tools and emerging technologies. Diagn Microbiol Infect Dis 2014; 78: 1-8. 